Article

\title{
Optimization of a Green Extraction/Inclusion Complex Formation Process to Recover Antioxidant Polyphenols from Oak Acorn Husks (Quercus Robur) Using Aqueous 2-Hydroxypropyl- $\beta$-Cyclodextrin/Glycerol Mixtures
}

\author{
Katerina Kyriakidou ${ }^{1}$, Ioannis Mourtzinos ${ }^{2}$, Costas G. Biliaderis ${ }^{2}$ and Dimitris P. Makris ${ }^{1, *}$ \\ 1 School of Environment, University of the Aegean, Mitr. Ioakim Street, Myrina 81400, Lemnos, Greece; \\ fns10045@fns.aegean.gr \\ 2 Faculty of Agriculture, Forestry \& Natural Environment, Aristotle University of Thessaloniki, P.O. Box 235, \\ Thessaloniki 54124, Greece; mourtzinos@agro.auth.gr (I.M.); biliader@agro.auth.gr (C.G.B.) \\ * Correspondence: dmakris@aegean.gr; Tel.: +30-225-408-3114
}

Academic Editor: Yu-Pin Lin

Received: 2 December 2015; Accepted: 22 January 2016; Published: 2 February 2016

\begin{abstract}
Aqueous mixtures of glycerol and 2-hydroxypropyl- $\beta$-cyclodextrin (CD), two non-toxic eco-friendly substances, were used as a means of extracting antioxidant polyphenols from oak acorn (Quercur robur) husks. The process was optimized by implementing a central composite (Box-Behnken) experimental design and response surface methodology, taking into consideration the critical parameters (independent variables) of glycerol concentration $\left(C_{\mathrm{gl}}\right), \mathrm{CD}$ concentration $\left(C_{C D}\right)$ and temperature $(T)$. The assessment of the extraction model was based on three responses: the total polyphenol yield $\left(\mathrm{Y}_{\mathrm{TP}}\right)$, the antiradical activity $\left(\mathrm{A}_{\mathrm{AR}}\right)$ and the reducing power $\left(\mathrm{P}_{\mathrm{R}}\right)$. The model illustrated that $Y_{\mathrm{TP}}$ depended significantly on $C_{\mathrm{gl}}$ and $C_{\mathrm{CD}}$, but not on $\mathrm{T}$, whereas both antioxidant properties considered $\left(\mathrm{A}_{\mathrm{AR}}\right.$ and $\left.\mathrm{P}_{\mathrm{R}}\right)$ were temperature-dependent. The maximum predicted $\mathrm{Y}_{T P}$ was $122.19 \mathrm{mg}$ GAE per $\mathrm{g}$ dry husk weight, while the extract obtained under optimized conditions displayed strong antioxidant activity.
\end{abstract}

Keywords: antioxidants; hydroxypropyl- $\beta$-cyclodextrin; inclusion formation; glycerol; oak acorns; polyphenols

\section{Introduction}

The demand for renewable chemicals is nowadays directing industrial practices towards manufacturing procedures with higher sustainability to minimize waste generation, improve cost-effectiveness, reduce energy consumption and meet customers' demand [1]. Agri-food waste valorization is a concept that has attracted important attention over the past few years, under the recognition that the development of innovative strategies could contribute to the exploitation of residual materials. The rational exploitation of waste plant material is largely based on white biotechnology and environmentally benign physico-chemical processes, aimed at fully utilizing the bio-organic constituents, and in this regard green extraction is a notion based on the principles of green engineering and green chemistry, which promotes sustainable extraction processes as a result of using non petroleum-based solvents and renewable plant material [2]. A holistic, 5-stages recovery process for the extraction of valuable compounds from natural products has been described by Galanakis [3].

Molecular inclusion is a method of encapsulation during which the guest molecule is incorporated in a biopolymer which contains a cavity. The biopolymers, otherwise called host molecules, are often 
cyclodextrins, a group of cyclic oligosaccharides that have the structure of a truncated cone enabling the formation of inclusion complexes with phenolic rings [4]. Encapsulation is a technique that is widely used in food processing and pharmaceutical formulations, as it facilitates the handling of unstable substances by averting degradation caused by environmental conditions, while it also improves processability by ameliorating physical properties like solubility and dispersibility $[5,6]$. Aqueous solutions of cyclodextrins can be considered as alternative, green solvents because, via the formation of complexes between the hydrophobic CD cavities and non-polar compounds, reduction of the system energy is achieved [7].

Likewise, glycerol is an abundant bio-solvent of low cost because it is a by-product of the bio-diesel industry, it possesses no toxicity, it is not flammable and has a high boiling point. These unique features make glycerol an ideal solvent, which could have an important perspective in the production of functional polyphenol-containing extracts. Recent studies pertaining to eco-friendly extraction methodologies demonstrated that aqueous glycerol mixtures might constitute a very suitable extraction medium for polyphenol recovery, since it possesses relatively low dielectric constant, which has been claimed to be a key characteristic regarding its efficiency in dissolving polyphenols that are otherwise sparingly soluble in water $[8,9]$.

Acorns are largely produced by oak trees during the period between the end of November to the end of December, and proximate analyses have revealed acorn chemical composition to be similar to chaffy cereals [10]. Acorns are used as pig feed and they have been shown to have a significant polyphenolic load and antioxidant activity [11], but the use of acorn in the human diet and folk medicine has also been reported [12,13]. The beneficial effects of acorn extracts have been attributed to the richness in polyphenols, which occur in relatively high levels, reaching $14.93 \%$ per dry weight [14]. Apart from gallic acid, several other biologically active compounds with antioxidant activity are present in acorns, including ellagic acid and different galloyl and hexahydroxydiphenoyl derivatives. Recent studies have indicated that the acorns $[15,16]$ and acorn husks [17] may contain high amounts of polyphenols with associated antioxidant effects [18].

However, there are no reports whatsoever regarding the extraction of polyphenolic substances from acorn husks and estimation of the antioxidant properties of the extracts. This investigation, therefore, is aimed at performing an optimization of an extraction process for the efficient recovery of polyphenols from oak acorn husks, using eco-friendly and non-toxic water/glycerol/2-hydroxypropyl- $\beta$-cyclodextrin mixtures. The optimization was based on a Box-Behnken experimental design, and the responses considered were the total polyphenol yield $\left(\mathrm{Y}_{\mathrm{TP}}\right)$, the antiradical activity $\left(\mathrm{A}_{\mathrm{AR}}\right)$ and the reducing power $\left(\mathrm{P}_{\mathrm{R}}\right)$ of the extracts.

\section{Method and Materials}

\subsection{Chemicals and Reagents}

Folin-Ciocalteu phenol reagent was from Fluka (Sigma-Aldrich: Steinheim, Germany). 2-Hydroxypropyl- $\beta$-cyclodextrin (CD, average MW 1460), gallic acid, ascorbic acid, trolox ${ }^{\mathrm{TM}}$, 2,4,6-tripyridyl-s-triazine (TPTZ) and 2,2-diphenyl-picrylhydrazyl (DPPH) stable radical were from Sigma Chemical Co. (St. Louis, MO, USA.). Glycerol (>99\%) was from Fisher Scientific (New Jersey, NJ, USA.).

\subsection{Plant Material}

Acorn fruits, without apparent damages and infections, were collected from Quercus robur trees that grow naturally, in the Evros prefecture (Thrace, Northern Greece), in November 2014. The fruits were transferred to the laboratory within a few hours and acorn husks (pericarp or fruit wall) were manually separated from the cupule and the nut with a sharp cutter, meshed and dried in an oven. Dried husks were stored at $-20^{\circ} \mathrm{C}$ until used. 


\subsection{Extraction Procedure}

An amount of $0.4 \mathrm{~g}$ of dried and grounded acorn husk was mixed with $20 \mathrm{~mL}$ of solvent (liquid-to-solid ratio $\left.50 \mathrm{~mL} \cdot \mathrm{g}^{-1}\right)$, composed of varying concentrations of water $(40 \%-100 \% w / v)$, glycerol $(0 \%-60 \% w / v)$ and CD $(1 \%-13 \% w / v)$ in a stoppered glass bottle. The material was subjected to extraction under stirring at $600 \mathrm{rpm}$ for $180 \mathrm{~min}$ in a water bath at three different temperatures $(40,60$, and $80 \pm 1^{\circ} \mathrm{C}$ ). Following extraction, samples were centrifuged in a table centrifuge (Hermle Z300K, Hermle: Wehingen, Germany) at $5000 \mathrm{rpm}$ for $10 \mathrm{~min}$. The clear supernatant was stored at $-20^{\circ} \mathrm{C}$ until used for further analysis.

\subsection{Determination of Total Polyphenol Yield $\left(Y_{T P}\right)$}

The concentration of total polyphenols in the extracts $\left(C_{\mathrm{TP}}\right)$ was determined according to a well-established protocol [19], using the Folin-Ciocalteu methodology. Yield in total polyphenols ( $\left.\mathrm{Y}_{\mathrm{TP}}\right)$ was expressed as mg gallic acid equivalents (GAE) per $\mathrm{g}$ of dry acorn husk weight.

\subsection{Determination of the Antiradical Activity $\left(A_{A R}\right)$}

For $\mathrm{A}_{\mathrm{AR}}$ determination, a previously described protocol was essentially used [20]. Briefly, an aliquot of $0.025 \mathrm{~mL}$ of sample was added to $0.975 \mathrm{~mL}$ DPPH solution $(100 \mu \mathrm{M}$ in $\mathrm{MeOH})$, and the absorbance was read at $t=0$ and $t=30 \mathrm{~min}$. Trolox ${ }^{\mathrm{TM}}$ equivalents ( $\mathrm{mM} \mathrm{TRE)} \mathrm{were} \mathrm{determined} \mathrm{from}$ linear regression, after plotting $\% \Delta \mathrm{A}_{515}$ of known solutions of trolox ${ }^{\mathrm{TM}}$ against concentration, where

$$
\% \Delta A_{515}=\frac{A_{515}^{t=0}-A_{515}^{t=30}}{A_{515}^{t=0}} \times 100
$$

Results were expressed as $\mu \mathrm{mol}$ TRE per g of dry acorn husk weight.

\subsection{Determination of the Reducing Power $\left(P_{R}\right)$}

A previously reported methodology was employed [18]. A sample aliquot (0.05 $\mathrm{mL})$ was mixed with a $0.05-\mathrm{mL} \mathrm{FeCl}_{3}$ solution $(4 \mathrm{mM}$ in $0.05 \mathrm{M} \mathrm{HCl})$, and incubated for $30 \mathrm{~min}$ in a water bath at $37^{\circ} \mathrm{C}$. Following this, a $0.9-\mathrm{mL}$ TPTZ solution $(1 \mathrm{mM}$ in $0.05 \mathrm{M} \mathrm{HCl})$ was added, and the absorbance was recorded at $620 \mathrm{~nm}$ after exactly $5 \mathrm{~min}$. $P_{R}$ was determined as $\mu \mathrm{mol}$ ascorbic acid equivalents $(\mu \mathrm{mol}$ AAE) per g of dry weight.

\subsection{Experimental Design}

A $2^{3}$-full factorial, central composite design was used to identify the relationship between the response functions and process variables, as well as to determine those conditions that optimized the simultaneous extraction/inclusion complex formation process. The three independent variables or factors studied were 2-hydroxypropyl- $\beta$-cyclodextrin concentration $\left(C_{\mathrm{CD}}\right)$, varying between $1 \%$ and $13 \%(w / v)$, glycerol concentration $\left(C_{\mathrm{gl}}\right)$, varying between $0 \%$ and $60 \%(w / v)$ and temperature $(\mathrm{T})$, varying between $40{ }^{\circ} \mathrm{C}$ and $80^{\circ} \mathrm{C}$. Value ranges were chosen on the basis of preliminary experimentation and previous studies [8,9]. Each variable to be optimized was coded at three levels, $-1,0$ and 1 (Table 1). The three independent variables were coded according to the following equation:

$$
x_{i}=\frac{X_{i}-X_{0}}{\Delta X_{i}}, x_{i}=1,2,3
$$

Where $x_{\mathrm{i}}$ and $X_{\mathrm{i}}$ are dimensionless, and the actual value of the independent variable $\mathrm{i}, X_{0}$ is the actual value of the independent variable $i$ at the central point, and $\Delta X_{i}$ is the step change of $X_{i}$ corresponding to a unit variation of the dimensionless value. The extraction yield $\left(\mathrm{Y}_{\mathrm{TP}}\right)$, the antiradical activity $\left(\mathrm{A}_{\mathrm{AR}}\right)$ and the reducing power $\left(P_{R}\right)$ were chosen as the dependent variables or responses because of their well-known respective dependency on the extraction process [21,22]. 
Table 1. Experimental values and coded levels of the independent variables used for the $2^{3}$ full-factorial design.

\begin{tabular}{ccccc}
\hline Independent Variables & Code Units & \multicolumn{3}{c}{ Coded Variable Level } \\
\hline & & -1 & 0 & 1 \\
$C_{\mathrm{CD}}(\%, w / v)$ & $\mathrm{X}_{1}$ & 1 & 7 & 13 \\
$C_{\mathrm{gl}}(\%, w / v)$ & $\mathrm{X}_{2}$ & 0 & 30 & 60 \\
$\mathrm{~T}\left({ }^{\circ} \mathrm{C}\right)$ & $\mathrm{X}_{3}$ & 40 & 60 & 80 \\
\hline
\end{tabular}

The data obtained were subjected to regression analysis using least square methodology to extract the equations that described the response values as a function of the independent variables (mathematical models). Analysis of variance (ANOVA) was used to assess the statistical significance of the model. Insignificant dependent terms $(p>0.05)$ were omitted from the regression models obtained, through a "backward elimination" process. Contour plots were obtained using the fitted model.

\subsection{Statistical Analysis}

Extractions were repeated twice and all determinations were carried out in triplicate. The values obtained were averaged. The experiment design and response surface statistics were performed with JMP ${ }^{\mathrm{TM}} 10$.

\section{Results and Discussion}

The screening carried out was designed to evaluate the effect of three selected variables, that is, the $C D$ concentration $\left(C_{C D}\right)$, glycerol concentration $\left(C_{\mathrm{gl}}\right)$ and temperature $(T)$. The values of the responses $\left(\mathrm{Y}_{\mathrm{TP}}, \mathrm{A}_{\mathrm{AR}}\right.$ and $\left.\mathrm{P}_{\mathrm{R}}\right)$ obtained experimentally were analyzed by multiple regression and after removal of the non-significant factors $(p>0.05)$, the theoretical models were as shown in Table 2 . The significance of model fitting was assessed using the square coefficient of correlation $\left(R^{2}\right)$, which was over than $0.93(p<0.05)$. This outcome clearly pointed to a statistically significant match between observed and predicted responses, and that the models given in Table 2 can predict the optimal experimental conditions with high reliability. Values of the independent process variables $\left(\mathrm{X}_{1}, \mathrm{X}_{2}\right.$ and $X_{3}$ ) considered, as well as measured and predicted values for all responses, are analytically given in Table 3. The variation in $Y_{T P}, A_{A R}$ and $P_{R}$ as a function of simultaneous variation in the process variables were given in the form of contour plots. As can be seen, maximization of $Y_{T P}$ levels (red colour) was observed when both $C_{\mathrm{CD}}$ and $C_{\mathrm{gl}}$ varied within 0.0 to 1.0 (coded values) and $\mathrm{T}$ within 0.5 to 1.0 (Figure 1). On the other hand, $\mathrm{A}_{\mathrm{AR}}$ maximization appeared to occur within particularly narrower limits, pointing essentially to values of 1.0, 1.0 and 1.0 for $C_{\mathrm{CD}}, C_{\mathrm{gl}}$ and $\mathrm{T}$, respectively (Figure 2). A similar pattern was observed for $P_{R}$, the maximization of which was shown to occur at a $C_{C D}$ values of 0.5-1.0 and $C_{\mathrm{gl}}$ and $\mathrm{T}$ values of 1.0, respectively (Figure 3).
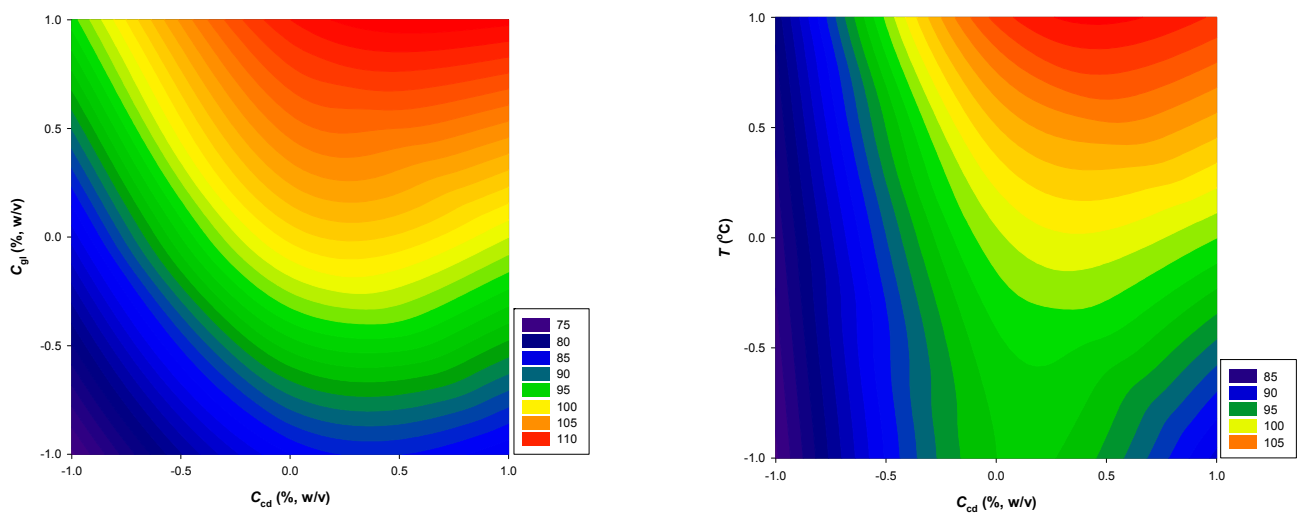

Figure 1. Cont. 


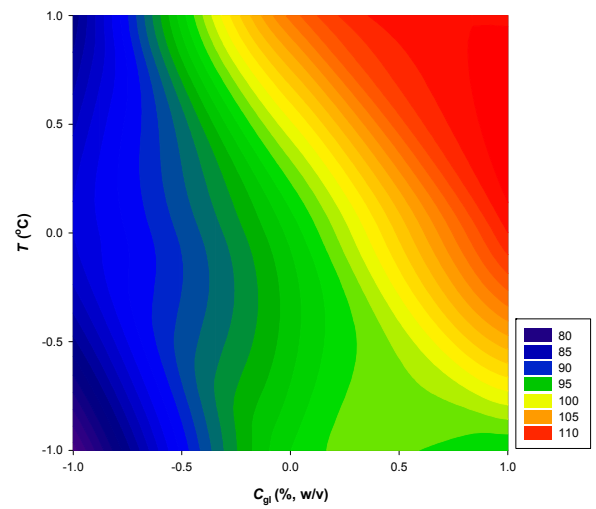

Figure 1. Contour plots illustrating the effect of the independent variables considered on the $\mathrm{Y}_{\mathrm{TP}}$. The upper left, upper right and lower plots show the effect of simultaneous variation of $C_{\mathrm{gl}}$ and $C_{\mathrm{CD}}, T$ and $C_{C D}$ and $T$ and $C_{\text {gl }}$, respectively (numbers on the axes correspond to coded values). Extractions of oak acorn husks were carried out under stirring at $600 \mathrm{rpm}$, for $180 \mathrm{~min}$ and a liquid-to-solid ratio of $50 \mathrm{~mL} \cdot \mathrm{g}^{-1}$.
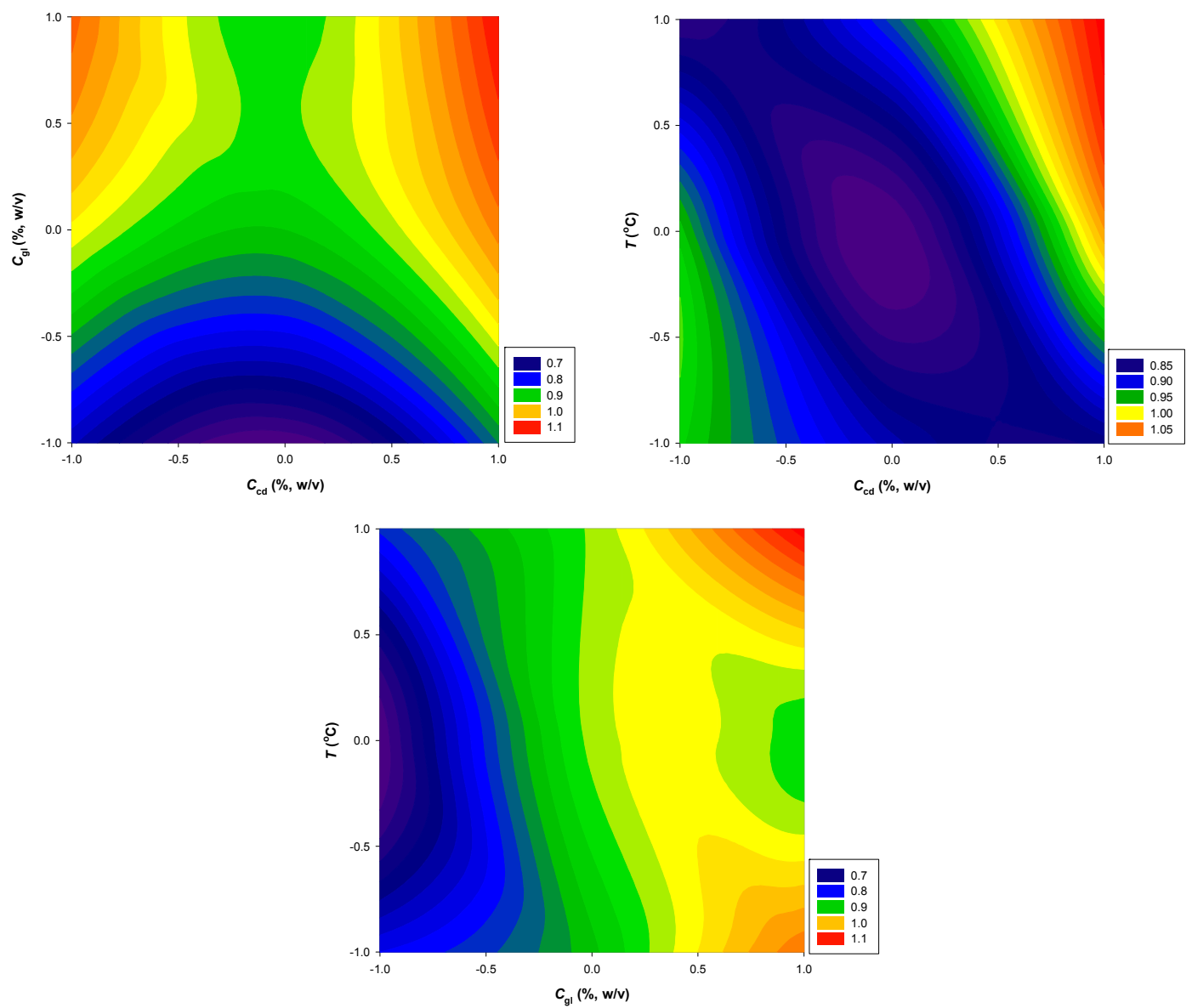

Figure 2. Contour plots illustrating the effect of the independent variables considered on the $\mathrm{A}_{\mathrm{AR}}$. The upper left, upper right and lower plots show the effect of simultaneous variation of $C_{\mathrm{gl}}$ and $C_{\mathrm{CD}}, T$ and $C_{\mathrm{CD}}$ and $T$ and $C_{\mathrm{gl}}$, respectively (numbers on the axes correspond to coded values). Extractions of oak acorn husks were carried out under stirring at $600 \mathrm{rpm}$, for $180 \mathrm{~min}$ and a liquid-to-solid ratio of $50 \mathrm{~mL} \cdot \mathrm{g}^{-1}$. 

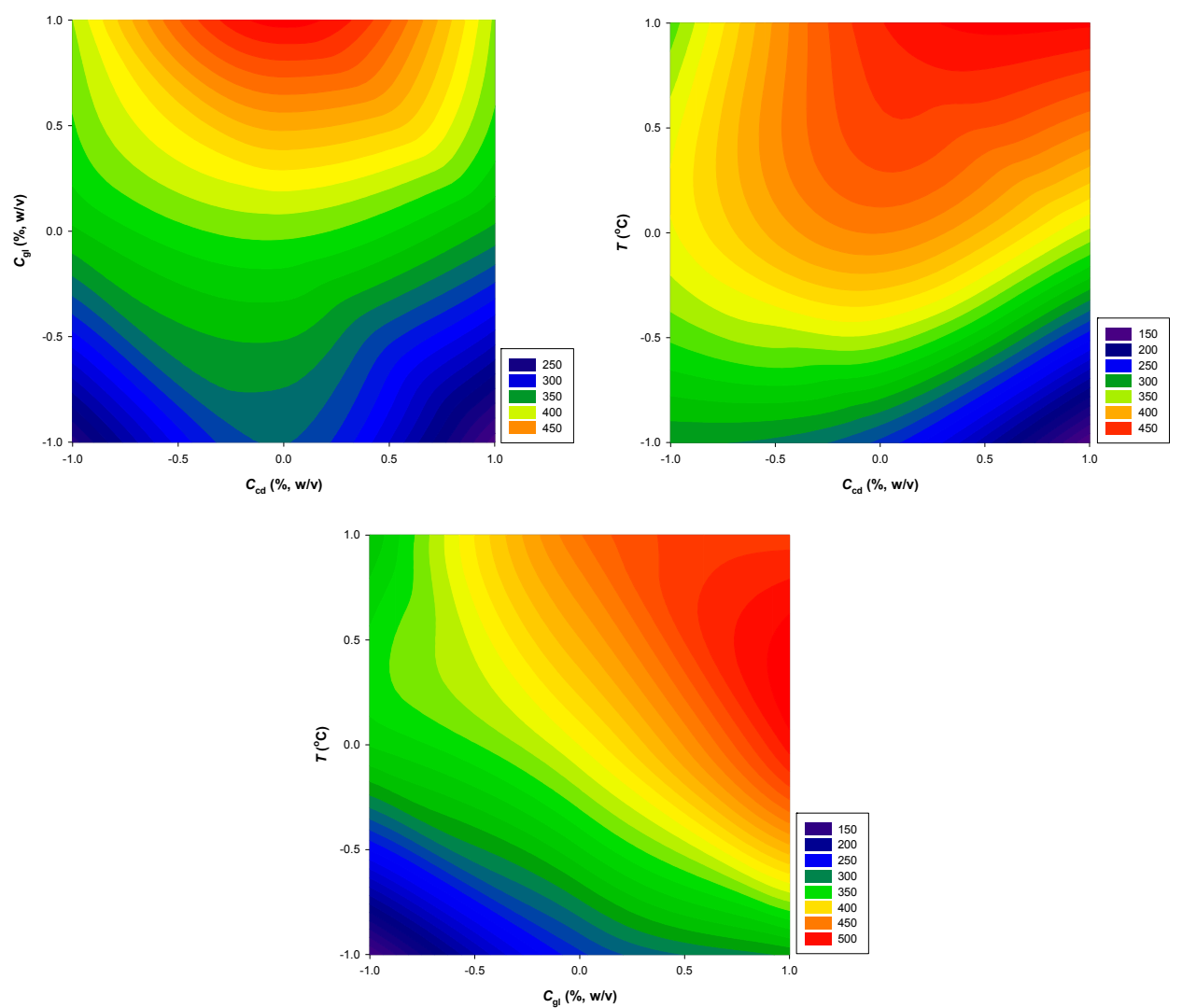

Figure 3. Contour plots illustrating the effect of the independent variables considered on the $P_{R}$. The upper left, upper right and lower plots show the effect of simultaneous variation of $C_{\mathrm{gl}}$ and $C_{\mathrm{CD}}, T$ and $C_{\mathrm{CD}}$ and $T$ and $C_{\mathrm{gl}}$, respectively (numbers on the axes correspond to coded values). Extractions of oak acorn husks were carried out under stirring at $600 \mathrm{rpm}$, for $180 \mathrm{~min}$ and a liquid-to-solid ratio of $50 \mathrm{~mL} \cdot \mathrm{g}^{-1}$.

For $\mathrm{Y}_{\mathrm{TP}}$, the significant terms of the mathematical model were $C_{\mathrm{CD}}$ and $C_{\mathrm{gl}}$, whereas $\mathrm{T}$ had a non-significant effect $(p>0.05)$. This finding suggests that the amount of both glycerol and CD largely defined $Y_{T P}$ within the limits specified by the experimental design (Table 1). With regard to $C_{\mathrm{gl}}$, the results obtained were in accordance with previous investigations, which showed that increases in $C_{\mathrm{gl}}$ up to $70 \%(w / v)$ favored polyphenol extraction from apple peels [8]. A similar trend was also reported for polyphenol extraction from two Artemisia species, where the higher yield was achieved with $90 \%(w / v)$ glycerol [9]. Such behavior was ascribed to polarity modifications induced by glycerol, which enabled solubilization of polyphenols of low solubility in water. Glycerol may facilitate the extraction of relatively polar molecules, as shown for olive leaf extracts produced with $10 \%(w / v)$ aqueous glycerol, in comparison with extracts obtained with water/ethanol [23].

Table 2. Polynomial equations and statistical parameters calculated after implementation of a $2^{3}$-full factorial, central composite experimental design.

\begin{tabular}{cccc}
\hline Response Variables & 2nd Order Polynomial Equations & $\boldsymbol{R}^{\mathbf{2}}$ & $\boldsymbol{p}$ \\
\hline $\mathrm{Y}_{\mathrm{TP}}\left(\mathrm{mg} \mathrm{GAE} \mathrm{g}^{-1} \cdot \mathrm{dw}\right)$ & $99.47+6.82 \mathrm{X}_{1}+12.00 \mathrm{X}_{2}$ & 0.95 & 0.0308 \\
$\mathrm{~A}_{\mathrm{AR}}\left(\mu \mathrm{mol} \mathrm{TRE} \mathrm{g}{ }^{-1} \cdot \mathrm{dw}\right)$ & $860.4+0.14 \mathrm{X}_{2}+0.09 \mathrm{X}_{1} \mathrm{X}_{3}+0.13 \mathrm{X}_{1}^{2}-0.1 \mathrm{X}_{2}^{2}$ & 0.96 & 0.0166 \\
$\mathrm{P}_{\mathrm{R}}\left(\mu \mathrm{mol} \mathrm{AAE} \mathrm{g}{ }^{-1} \cdot \mathrm{dw}\right)$ & $408.1+81.8 \mathrm{X}_{2}+69.7 \mathrm{X}_{1} \mathrm{X}_{3}$ & 0.94 & 0.0418 \\
\hline
\end{tabular}


Table 3. Measured and predicted $Y_{T P}, A_{A R}$ and $P_{R}$ values determined for the individual design points.

\begin{tabular}{|c|c|c|c|c|c|c|c|c|c|}
\hline \multirow[t]{3}{*}{$\begin{array}{c}\text { Design } \\
\text { Point }\end{array}$} & \multicolumn{3}{|c|}{$\begin{array}{c}\text { Independent } \\
\text { Variables }\end{array}$} & \multicolumn{6}{|c|}{ Responses } \\
\hline & \multirow[b]{2}{*}{$X_{1}$} & \multirow[b]{2}{*}{$X_{2}$} & \multirow[b]{2}{*}{$X_{3}$} & \multicolumn{2}{|c|}{$\mathrm{Y}_{\mathrm{TP}}\left(\mathrm{mg} \mathrm{GAE} \mathrm{g}^{-1} \cdot \mathrm{dw}\right)$} & \multicolumn{2}{|c|}{$\mathrm{A}_{\mathrm{AR}}\left(\mu \mathrm{mol}\right.$ TRE $\left.\mathrm{g}^{-1} \cdot \mathrm{dw}\right)$} & \multicolumn{2}{|c|}{$P_{R}\left(\mu \mathrm{mol}\right.$ AAE $\left.g^{-1} \cdot d w\right)$} \\
\hline & & & & Measured & Predicted & Measured & Predicted & Measured & Predicted \\
\hline 1 & -1 & -1 & -1 & 72.73 & 74.21 & 862.8 & 822.9 & 237.5 & 209.4 \\
\hline 2 & -1 & -1 & 1 & 72.73 & 73.21 & 672.8 & 665.4 & 237.5 & 261.2 \\
\hline 3 & -1 & 1 & -1 & 90.91 & 91.41 & 1063.6 & 1101.3 & 377.6 & 373.0 \\
\hline 4 & -1 & 1 & 1 & 100.00 & 99.50 & 986.7 & 995.3 & 457.7 & 406.2 \\
\hline 5 & 1 & -1 & -1 & 77.27 & 78.80 & 746.6 & 736.9 & 482.0 & 491.7 \\
\hline 6 & 1 & -1 & 1 & 90.91 & 91.40 & 981.7 & 942.9 & 377.6 & 379.9 \\
\hline 7 & 1 & 1 & -1 & 100.00 & 100.50 & 966.0 & 971.8 & 257.5 & 231.4 \\
\hline 8 & 1 & 1 & 1 & 122.73 & 122.19 & 1190.9 & 1229.3 & 517.8 & 543.5 \\
\hline 9 & -1 & 0 & 0 & 86.36 & 84.37 & 952.3 & 954.0 & 297.6 & 358.1 \\
\hline 10 & 1 & 0 & 0 & 100.09 & 98.01 & 1023.4 & 1028.0 & 397.7 & 346.7 \\
\hline 11 & 0 & -1 & 0 & 90.45 & 85.98 & 526.4 & 622.8 & 377.6 & 330.7 \\
\hline 12 & 0 & 1 & 0 & 107.00 & 109.98 & 994.6 & 905.2 & 437.7 & 494.3 \\
\hline 13 & 0 & 0 & -1 & 100.00 & 95.98 & 866.5 & 874.1 & 257.5 & 267.1 \\
\hline 14 & 0 & 0 & 1 & 95.45 & 106.33 & 901.2 & 924.1 & 397.7 & 449.0 \\
\hline 15 & 0 & 0 & 0 & 100.00 & 99.47 & 931.3 & 860.4 & 437.7 & 408.1 \\
\hline 16 & 0 & 0 & 0 & 90.91 & 99.47 & 803.9 & 860.4 & 397.7 & 408.1 \\
\hline
\end{tabular}

On the other hand, the non-significant effect of temperature was quite a paradox, since solubilization of polyphenols such as catechin has been proven to be endothermic and hence thermodynamically favored at higher temperatures [24]. This effect has been demonstrated in several cases of solid-liquid polyphenol extraction, where increased temperatures favored increased extraction yield $[8,9,25]$. A rational explanation would be that, if the polyphenols occurring in acorn husks are readily soluble in the extraction medium used, a large amount would be rapidly extracted even at regular ambient temperature; thus, a further increase in temperature would have a rather non-significant contribution to the overall yield. Another possibility could be the considerably compact cell wall structures of the husk particles, imposing diffusion limitations to the extraction process; following initial solubilization of the relatively accessible phenolics, the remaining portion of phenolics is strongly bound within the plant tissue matrix and cannot be retrieved unless further pulverization of the husk material is carried out. In this case, the role of both glycerol and CD would become important, assuming that they could have a prominent effect in solubilizing the acorn husk polyphenols.

Indeed, the mathematical model revealed a positive effect of $C_{\mathrm{CD}}$ (Table 2), which suggested that increasing $C_{\mathrm{CD}}$ up to $13 \%(w / v)$ contributed in obtaining higher $\mathrm{Y}_{\mathrm{TP}}$. Such a phenomenon would be reasonably anticipated because ligand inclusion in the CD cavity is a stoichiometric phenomenon and usually only one molecule may be incorporated into the cavity so as to become entrapped. This fact is corroborated by studies using single-polyphenol solutions and $\beta$-cyclodextrin, where the molecular stoichiometry observed was 1:1 [26-29]. Thus, increased CD enabled the entrapment of more polyphenol molecules that diffused from the solid particles, leading to higher solubilization in the liquid phase [30-32], hence the higher $\mathrm{Y}_{\mathrm{TP}}$.

The $\mathrm{A}_{\mathrm{AR}}$ of the extracts was positively influenced by $C_{\mathrm{gl}}$, but the interaction term of $C_{\mathrm{CD}}$ with $\mathrm{T}$ and the quadratic term of $C_{\mathrm{gl}}$ have also had a significant and positive effect. On the contrary, the quadratic term of $C_{\mathrm{gl}}$ had a negative effect on $\mathrm{A}_{\mathrm{AR}}$ (Table 2). The trend recorded for $\mathrm{P}_{\mathrm{R}}$ shared some similar features, but no quadratic terms of any variable tested were significant. The optimization pattern was also very different, as judged by the visualized effect of simultaneous variation of the process variables (Figure 3). The positive effect exerted by $C_{\mathrm{gl}}$ on both $\mathrm{A}_{\mathrm{AR}}$ and $\mathrm{P}_{\mathrm{R}}$ could be ascribed to the fact that the higher $C_{\mathrm{gl}}$ promoted higher $\mathrm{Y}_{\mathrm{TP}}$. In several instances, the antioxidant effects manifested by polyphenol-containing extracts are directly proportional to polyphenol concentration [33], although this is not a universal principle because of phenomena of synergism and/or antagonism amongst different polyphenols [34]. However, it is likely that similar phenomena amongst the entrapped 
polyphenols could be hindered owed to steric effects; their impact would therefore be quite minimal, if not null. Thus, extracts enriched in polyphenols would be normally expected to exhibit stronger antioxidant potency. Furthermore, inclusion of polyphenols in CD has been shown in several instances to enhance the antioxidant potency $[25,28,35,36]$, mainly by enhancing polyphenol solubility, although contrasting results have also been reported [37].

The use of the mathematical models permitted the determination of the optimal set of conditions and the maximum predicted $Y_{T P}, A_{A R}$ and $P_{R}$ values. The determination was based on the simultaneous maximization of the desirability function, which provided the optimal values for all process variables considered (Figure 4). The maximum desirability (0.93) was achieved with $C_{\mathrm{CD}}=13 \%(w / v), C_{\mathrm{gl}}=60 \%(w / v)$ and $\mathrm{T}=80{ }^{\circ} \mathrm{C}$. Under these conditions, the maximum values estimated were $\mathrm{Y}_{\mathrm{TP}}=122.19 \pm 13.99 \mathrm{mg} \mathrm{GAE} \mathrm{g}{ }^{-1} \cdot \mathrm{dw}, \mathrm{A}_{\mathrm{AR}}=1209.8 \pm 153.2 \mu \mathrm{mol} \mathrm{TRE} \mathrm{g} \mathrm{T}^{-1} \cdot \mathrm{dw}$ and $\mathrm{P}_{\mathrm{R}}=555.8 \pm 148.8 \mu \mathrm{mol} \mathrm{AAE} \mathrm{g}^{-1} \cdot \mathrm{dw}$. The $\mathrm{Y}_{\mathrm{TP}}$ value is significantly higher than those reported for other agri-food residues, such as onion solid wastes extracted with aqueous glycerol, which were shown to have a polyphenol content as high as $93.42 \mathrm{mg} \mathrm{GAE} \mathrm{g}^{-1} \cdot \mathrm{dw}, \mathrm{A}_{\mathrm{AR}}=720 \mu \mathrm{mol} \mathrm{TRE} \mathrm{g}{ }^{-1} \cdot \mathrm{dw}$ and $P_{R}=712 \mu \mathrm{mol} \mathrm{AAE} g^{-1} \cdot d w$ [22]. These findings indicated that oak acorn husks may be a very rich source in polyphenolic phytochemicals, with exceptionally high antioxidant potential. The latter is particularly significant because other waste biomaterials, such as pomegranate husks, which were also found to be very rich in ellagitannins, did not display antioxidant activity of proportional magnitude [38].

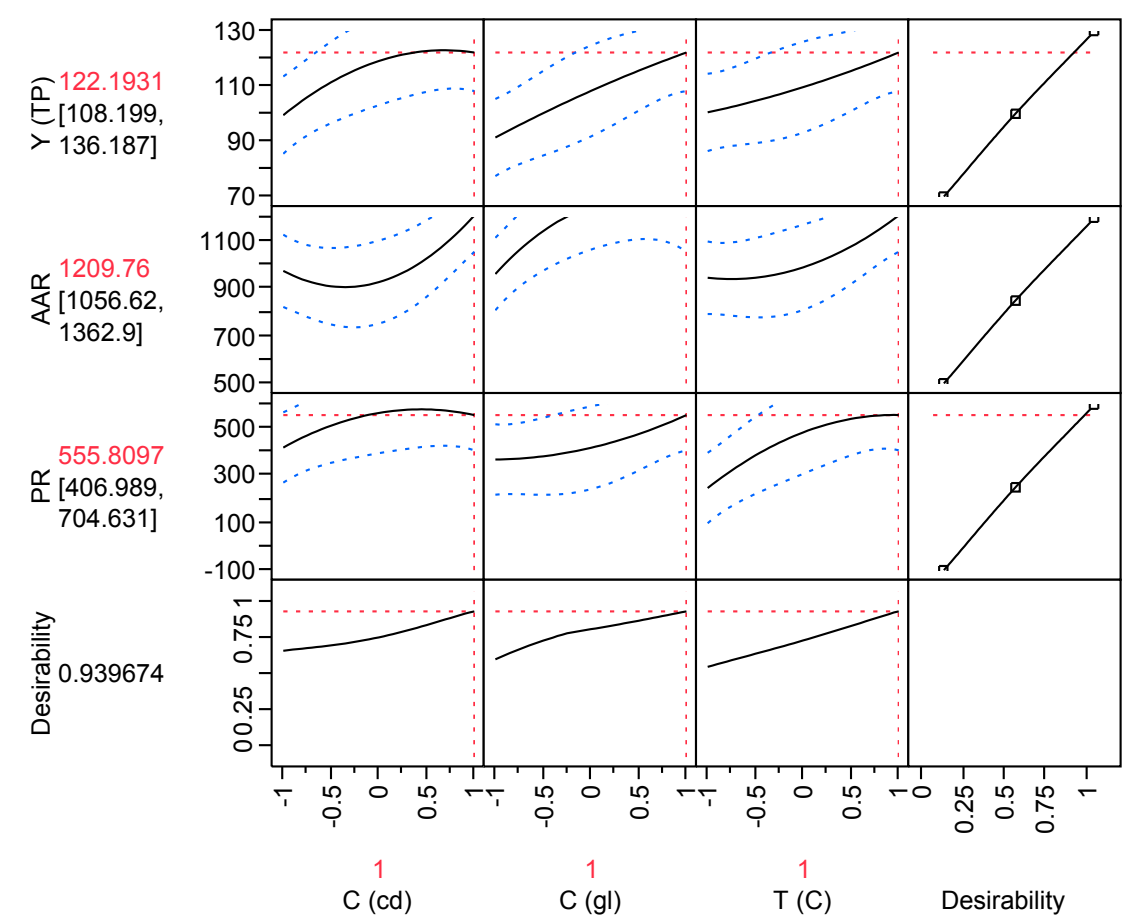

Figure 4. Prediction profiler displaying the overall desirability of the model, following adjustment of the independent variable at their optimal values. Extractions of oak acorn husks were carried out under stirring at $600 \mathrm{rpm}$, for $180 \mathrm{~min}$ and a liquid-to-solid ratio of $50 \mathrm{~mL} \cdot \mathrm{g}^{-1}$.

\section{Conclusions}

The study presented herein showed for the first time that a combination of glycerol and 2-hydroxypropyl- $\beta$-cyclodextrin, two non-toxic substances, might be a very effective co-solvent system regarding the extraction of antioxidant polyphenols from oak acorn husks, acting as a simultaneous extraction/inclusion system. The experimental design based on a response surface optimization methodology permitted the determination of the optimal set of conditions, which enabled the 
generation of extracts with enhanced antioxidant properties. The results indicate that the recovery yield in total polyphenols, as well as the antioxidant activity observed, may surpass the values reported in the literature for other agri-food waste extracts. In this respect, oak acorn husks may be considered a very rich source of functional constituents, with a high potential in developing bioactive formulations for the food, pharmaceutical and cosmetics industries.

Acknowledgments: The Department of Food Science \& Technology (Aristotle University of Thessaloniki) is thanked for providing all the means necessary to carry out this study.

Author Contributions: Katerina Kyriakidou, laboratory experiments; Ioannis Mourtzinos, laboratory experiments, experimental design, data handling; Costas G. Biliaderis, data interpretation, manuscript editing; Dimitris P. Makris, experimental design, data handling, statistics, manuscript editing.

Conflicts of Interest: The authors declare no conflict of interest.

\section{Abbreviations}

The following abbreviations are used in this manuscript:

$\begin{array}{ll}\mathrm{A}_{\mathrm{AR}} & \text { antiradical activity }\left(\mu \mathrm{mol} \mathrm{TRE} \mathrm{g}^{-1} \cdot \mathrm{dw}\right) \\ \mathrm{C}_{\mathrm{CD}} & \text { hydroxypropyl- } \beta \text {-cyclodextrin concentration }(\%, w / v) \\ \mathrm{C}_{\mathrm{gl}} & \text { glycerol concentration }(\%, w / v) \\ \mathrm{C}_{\mathrm{TP}} & \text { total polyphenol concentration }\left(\mathrm{mg} \mathrm{GAE} \mathrm{L}^{-1}\right) \\ \mathrm{P}_{\mathrm{R}} & \text { reducing power }\left(\mu \mathrm{mol} \mathrm{AAE} \mathrm{g}^{-1} \cdot \mathrm{dw}\right) \\ \mathrm{T} & \text { temperature }\left({ }^{\circ} \mathrm{C}\right) \\ \mathrm{Y}_{\mathrm{TP}} & \text { yield in total polyphenols }\left(\mathrm{mg} \mathrm{GAE}^{-1} \cdot \mathrm{dw}\right) \\ \mathrm{AAE} & \text { ascorbic acid equivalents } \\ \mathrm{CD} & \text { hydroxypropyl- } \beta \text {-cyclodextrin } \\ \mathrm{DPPH} & \text { 2,2-diphenyl-picrylhydrazyl } \\ \mathrm{GAE} & \text { gallic acid equivalents } \\ \mathrm{TRE} & \text { trolox equivalents } \\ \mathrm{TPTZ} & 2,4,6 \text {-tripyridyl-s-triazine }\end{array}$

\section{References}

1. Arancon, R.A.D.; Lin, C.S.K.; Chan, K.M.; Kwan, T.H.; Luque, R. Advances on waste valorization: New horizons for a more sustainable society. Energy Sci. Eng. 2013, 1, 53-71. [CrossRef]

2. Li, Y.; Fabiano-Tixier, A.S.; Tomao, V.; Cravotto, G.; Chemat, F. Green ultrasound-assisted extraction of carotenoids based on the bio-refinery concept using sunflower oil as an alternative solvent. Ultrasonics Sonochem. 2013, 20, 12-18. [CrossRef] [PubMed]

3. Galanakis, C.M. Recovery of high added-value components from food wastes: Conventional, emerging technologies and commercialized applications. Trends Food Sci. Tech. 2012, 26, 68-87. [CrossRef]

4. Pinho, E.; Grootveld, M.; Soares, G.; Henriques, M. Cyclodextrins as encapsulation agents for plant bioactive compounds. Carbohydrate Polym. 2014, 101, 121-135. [CrossRef] [PubMed]

5. Kuang, S.S.; Oliveira, J.C.; Crean, A.M. Microencapsulation as a tool for incorporating bioactive ingredients into food. Crit. Rev. Food Sci. Nutr. 2010, 50, 951-968. [CrossRef] [PubMed]

6. Neethirajan, S.; Jayas, D.S. Nanotechnology for the food and bioprocessing industries. Food Bioproc. Technol. 2011, 4, 39-47. [CrossRef]

7. Chemat, F.; Vian, M.A.; Cravotto, G. Green extraction of natural products: Concept and principles. Int. J. Mol. Sci. 2012, 13, 8615-8627. [CrossRef] [PubMed]

8. Blidi, S.; Bikaki, M.; Grigorakis, S.; Loupassaki, S.; Makris, D.P. A Comparative Evaluation of Bio-solvents for the Efficient Extraction of Polyphenolic Phytochemicals: Apple Waste Peels as a Case Study. Waste Biomass Valor. 2015, 6, 1125-1133. [CrossRef] 
9. Shehata, E.; Grigorakis, S.; Loupassaki, S.; Makris, D.P. Extraction optimization using water/glycerol for the efficient recovery of polyphenolic antioxidants from two Artemisia species. Separ. Purif. Technol. 2015, 149, 462-469. [CrossRef]

10. Ofcarcik, R.; Burns, E. Chemical and physical properties of selected acorns. J. Food Sci. 1971, 36, 576-578. [CrossRef]

11. Tejerina, D.; García-Torres, S.; de Vaca, M.C.; Vázquez, F.; Cava, R. Acorns (Quercus rotundifolia Lam.) and grass as natural sources of antioxidants and fatty acids in the "montanera" feeding of Iberian pig: Intra-and inter-annual variations. Food Chem. 2011, 124, 997-1004. [CrossRef]

12. Çoruh, N.; Nebigil, C.; Özgökce, F. Rapid and comprehensive separation for the phenolic constituents of Quercus brantii acorns by RP-HPLC-DAD. J. Liquid Chrom. Related Technol. 2014, 37, 907-915. [CrossRef]

13. Rakić, S.; Petrović, S.; Kukić, J.; Jadranin, M.; Tešević, V.; Povrenović, D.; Šiler-Marinković, S. Influence of thermal treatment on phenolic compounds and antioxidant properties of oak acorns from Serbia. Food Chem. 2007, 104, 830-834. [CrossRef]

14. Kosseva, M.; Webb, C. Food Industry Wastes: Assessment and Recuperation of Commodities; Academic Press: Amsterdam, The Netherlands, 2013.

15. Popović, B.M.; Štajner, D.; Ždero, R.; Orlović, S.; Galić, Z. Antioxidant characterization of oak extracts combining spectrophotometric assays and chemometrics. Sci. World J. 2013, 2013. [CrossRef] [PubMed]

16. Yin, Y.; Heo, S.-I.; Jung, M.-J.; Wang, M.-H. Antioxidant properties of water extract from acorn. J. Applied Biol. Chem. 2007, 50, 70-73.

17. Igueld, S.B.; Abidi, H.; Trabelsi-Ayadi, M.; Chérif, J.K. Study of physicochemicals characteristics and antioxidant capacity of cork oak acorns (Quercus suber L.) grown in three regions in Tunisia. J. Applied Pharmaceut. Sci. 2015, 5, 26-32. [CrossRef]

18. Karimi, A.; Moradi, M.-T. Total Phenolic Compounds and In Vitro Antioxidant Potential of Crude Methanol Extract and the Correspond Fractions of Quercus Brantii L. Acorn. J. Herb. Med. Pharmacol. 2015, 4, $35-39$.

19. Karakashov, B.; Grigorakis, S.; Loupassaki, S.; Makris, D.P. Optimization of polyphenol extraction from Hypericum perforatum (St. John's Wort) using aqueous glycerol and response surface methodology. J. Applied Res. Med. Arom. Plants 2015, 2, 1-8.

20. Bassil, D.; Makris, D.P.; Kefalas, P. Oxidation of caffeic acid in the presence of L-cysteine: Isolation of 2-S-cysteinylcaffeic acid and evaluation of its antioxidant properties. Food Res. Inter. 2005, 38, 395-402. [CrossRef]

21. Karvela, E.; Makris, D.P.; Kalogeropoulos, N.; Karathanos, V.T. Deployment of response surface methodology to optimise recovery of grape (Vitis vinifera) stem polyphenols. Talanta 2009, 79, 1311-1321. [CrossRef] [PubMed]

22. Kiassos, E.; Mylonaki, S.; Makris, D.P.; Kefalas, P. Implementation of response surface methodology to optimise extraction of onion (Allium cepa) solid waste phenolics. Innov. Food Sci. Emerg. Technol. 2009, 10, 246-252. [CrossRef]

23. Apostolakis, A.; Grigorakis, S.; Makris, D.P. Optimization and comparative kinetics study of polyphenol extraction from olive leaves (Olea europaea) using heated water/glycerol mixtures. Separ. Purif. Technol. 2014, 128, 89-95.

24. Cuevas-Valenzuela, J.; González-Rojas, Á.; Wisniak, J.; Apelblat, A.; Pérez-Correa, J. R. Solubility of (+)-catechin in water and water-ethanol mixtures within the temperature range 277.6-331.2 K: Fundamental data to design polyphenol extraction processes. Fluid Phase Equil. 2014, 382, 279-285.

25. Katsampa, P.; Valsamedou, E.; Grigorakis, S.; Makris, D.P. A green ultrasound-assisted extraction process for the recovery of antioxidant polyphenols and pigments from onion solid wastes using Box-Behnken experimental design and kinetics. Ind. Crops Prod. 2015, 77, 535-543. [CrossRef]

26. Alvarez-Parrilla, E.; Laura, A.; Torres-Rivas, F.; Rodrigo-Garcia, J.; González-Aguilar, G.A. Complexation of apple antioxidants: Chlorogenic acid, quercetin and rutin by $\beta$-cyclodextrin $(\beta-\mathrm{CD})$. J. Inclus. Phenom. Macrocyclic Chem. 2005, 53, 121-129. [CrossRef]

27. Calabrò, M.; Tommasini, S.; Donato, P.; Raneri, D.; Stancanelli, R.; Ficarra, P.; Ficarra, R.; Costa, C.; Catania, S.; Rustichelli, C. Effects of $\alpha$ - and $\beta$-cyclodextrin complexation on the physico-chemical properties and antioxidant activity of some 3-hydroxyflavones. J. Pharmaceut. Biomed. Anal. 2004, 35, 365-377. [CrossRef] [PubMed] 
28. Jullian, C.; Miranda, S.; Zapata-Torres, G.; Mendizábal, F.; Olea-Azar, C. Studies of inclusion complexes of natural and modified cyclodextrin with $(+)$ catechin by NMR and molecular modeling. Bioorg. Med. Chem. 2007, 15, 3217-3224. [CrossRef] [PubMed]

29. Tommasini, S.; Raneri, D.; Ficarra, R.; Calabrò, M.L.; Stancanelli, R.; Ficarra, P. Improvement in solubility and dissolution rate of flavonoids by complexation with $\beta$-cyclodextrin. J. Pharmaceut. Biomed. Anal. 2004, 35, 379-387. [CrossRef]

30. Bergonzi, M.C.; Bilia, A.R.; Di Bari, L.; Mazzi, G.; Vincieri, F.F. Studies on the interactions between some flavonols and cyclodextrins. Bioorg. Med. Chem. Letters 2007, 17, 5744-5748. [CrossRef] [PubMed]

31. Karathanos, V.T.; Mourtzinos, I.; Yannakopoulou, K.; Andrikopoulos, N.K. Study of the solubility, antioxidant activity and structure of inclusion complex of vanillin with $\beta$-cyclodextrin. Food Chem. 2007, 101, 652-658. [CrossRef]

32. Lucas-Abellán, C.; Fortea, M.; Gabaldón, J.; Núñez-Delicado, E. Complexation of resveratrol by native and modified cyclodextrins: determination of complexation constant by enzymatic, solubility and fluorimetric assays. Food Chem. 2008, 111, 262-267. [CrossRef]

33. Makris, D.P.; Boskou, G.; Andrikopoulos, N.K. Polyphenolic content and in vitro antioxidant characteristics of wine industry and other agri-food solid waste extracts. J. Food Compos. Anal. 2007, 20, 125-132. [CrossRef]

34. Karvela, E.; Makris, D.P.; Karathanos, V.T. Implementation of response surface methodology to assess the antiradical behaviour in mixtures of ascorbic acid and $\alpha$-tocopherol with grape (Vitis vinifera) stem extracts. Food Chem. 2012, 132, 351-359. [CrossRef] [PubMed]

35. Da Rocha Ferreira, F.; Valentim, I.B.; Ramones, E.L.C.; Trevisan, M.T.S.; Olea-Azar, C.; Perez-Cruz, F.; de Abreu, F.C.; Goulart, M.O.F. Antioxidant activity of the mangiferin inclusion complex with $\beta$-cyclodextrin. LWT-Food Sci. Technol. 2013, 51, 129-134. [CrossRef]

36. Stražišar, M.; Andrenšek, S.; Šmidovnik, A. Effect of $\beta$-cyclodextrin on antioxidant activity of coumaric acids. Food Chemistry 2008, 110, 636-642. [CrossRef]

37. Budryn, G.; Nebesny, E.; Pałecz, B.; Rachwał-Rosiak, D.; Hodurek, P.; Miśkiewicz, K.; Oracz, J.; Żyżelewicz, D. Inclusion complexes of $\beta$-cyclodextrin with chlorogenic acids (CHAs) from crude and purified aqueous extracts of green Robusta coffee beans (Coffea canephora L.). Food Res. Inter. 2014, 61, 202-213. [CrossRef]

38. Amyrgialaki, E.; Makris, D.P.; Mauromoustakos, A.; Kefalas, P. Optimization of the extraction of pomegranate (Punica granatum) husk phenolics using water/ethanol solvent systems and response surface methodology. Ind. Crops Prod. 2014, 59, 216-222. [CrossRef]

(c) 2016 by the authors; licensee MDPI, Basel, Switzerland. This article is an open access article distributed under the terms and conditions of the Creative Commons by Attribution (CC-BY) license (http:/ / creativecommons.org/licenses/by/4.0/). 